Military Technical College

Kobry El-Kobbah, Cairo, Egypt.

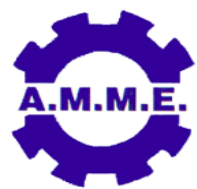

$16^{\text {th }}$ International Conference on Applied Mechanics and Mechanical Engineering.

\title{
EFFECT OF POURING TEMPERATURE AND WATER COOLING ON THE MICROSTRUCTURE OF INGOTS PRODUCED BY COOLING SLOPE CASTING TECHNIQUE
}

\author{
I. S. El-Mahallawi ${ }^{1}$, T. S. Mahmoud ${ }^{2}$, A. M. Gaafer ${ }^{2}$ and F.H. Mahmoud ${ }^{2}$
}

\begin{abstract}
The cooling slope (CS) casting is the simplest and cheapest technique for producing feedstock materials with non-dendritic microstructure required for semi-solid metal (SSM) processing methods such as thixoforming. In the present investigation, the effect of the pouring temperature and the water cooling on the thixotropic microstructure of commercial A319 Al-Si cast alloy was studied. The results showed that increasing the pouring temperature slightly reduces the bulk porosity of the CS ingots. The ingots poured with water-cooling exhibited slightly lower porosity content than those poured with without water-cooling. Generally, it has been found that the primary a-Al grains have generally higher shape factor near the edge of ingot than the middle and center. Ingots poured with water-cooling exhibited lower grain size and shape factor than those poured without water-cooling. Increasing the pouring temperature increases the size a-Al grains. Ingots poured with water-cooling exhibited higher hardness values than those poured without water-cooling.
\end{abstract}

\section{KEYWORDS}

Cooling Slope Casing, Microstructure, Thixotropic, Aluminium Alloys.

1 Mining, Petroleum and Metallurgical Department, Faculty of Engineering, Cairo University, Giza, Egypt.

2 Mechanical Engineering Department, Shoubra Faculty of Engineering, Benha University, Cairo, Egypt. 


\section{INTRODUCTION}

Thixoforming and thixocasting are semi-solid processing (SSP) technologies combining the near-net-shape capabilities of die-casting and mechanical properties of forging [1,2]. Parts produced by thixoforming techniques are reported to have substantially higher qualitythan die-castings and lower cost than forgings $[3,4]$. However, a special ingot with thixotropic (non-dendritic) microstructure is required forthixoforming. Therefore, ingots that are not made specifically for thixoforming, i.e. not possessing the appropriate microstructures, cannot be used. Several commercial aluminum alloys such as A356 and A357 were used as thixoforming materials [5-7]. These alloys provide high fluidity and good castability and usually used in fabrication automobile components.

Cooling slope (CS) casting is one of the simplest and cheapest techniques used to produce ingots for thixocasting and rheocasting [1,3]. In this technique, molten alloy with a superheat temperature is poured on an inclined plate. Solid nucleuses are formed because of the contact between the melt and the slope plate, detached from the surface because of the applied shear stress due to gravity force and melt flow. Ingots produced from CS casting have thixotropic microstructure required for thixoforming. In CS casting, various parameters such as superheat (pouring) temperature, length, angle, vibration, water-cooling, inclined plate material and mold material can affect the final microstructure $[1,3,8]$.

The effect of such parameters on the microstructural characteristics of the A356 and A357aluminum (AI-Si-Mg) alloys was extensively studied [1,3,8-11]. However, the effect of CS casting process parameters on other cast aluminum alloys such as A319 and A390 alloys still needs further investigation [12,13], despite the significance of these alloys in automotive industry. The A319 (Al-Si-Cu) cast aluminum alloy have a wide solidification range which makes it suitable for SSP [1418]. The A319 alloy exhibits good castability, weldability and corrosion resistance. The mechanical properties of the A319 alloy are not largely affected by fluctuations in impurity content. Typical uses of the A319 alloy are in permanent mold casting with applications including water-cooled cylinder heads, rear axle housings and engine parts.

The aim of the present investigation is to investigate the effect of pouring temperature and water-cooling on the microstructural characteristics of A319 aluminum alloy ingots produced by cooling slope casting.

\section{EXPERIMENTAL PROCEDURES}

In this study, commercial A319 Al-Si-Cu cast aluminium alloy was used. The composition of the A319 alloy is given in Table 1. To determine the solidus and liquidus temperatures, also the variation of melt liquid percent with temperature, the differential scanning calorimetric (DSC) analysis was carried out. The DSC experiments were carried during heating with a heating rate of $5^{\circ} \mathrm{C} / \mathrm{min}$. Figure 1 shows the resulted DSC curve of the A319 alloy. The figure also shows the curve representing the variation of liquid weight fraction with the temperature. This curve was obtained after integrating the area under DSC curve. Figure 1 shows that the 
Table 1. Chemical composition of A319 aluminum alloys (wt. \%).

\begin{tabular}{cccccccccc}
\hline Alloy & $\mathrm{Si}$ & $\mathrm{Fe}$ & $\mathrm{Cu}$ & $\mathrm{Mg}$ & $\mathrm{Mn}$ & $\mathrm{Ni}$ & $\mathrm{Zn}$ & $\mathrm{Ti}$ & $\mathrm{Al}$ \\
\hline $\mathrm{A} 319$ & 6.48 & 0.25 & 3.00 & 0.002 & 0.003 & 0.004 & 0.013 & 0.009 & Bal. \\
\hline
\end{tabular}

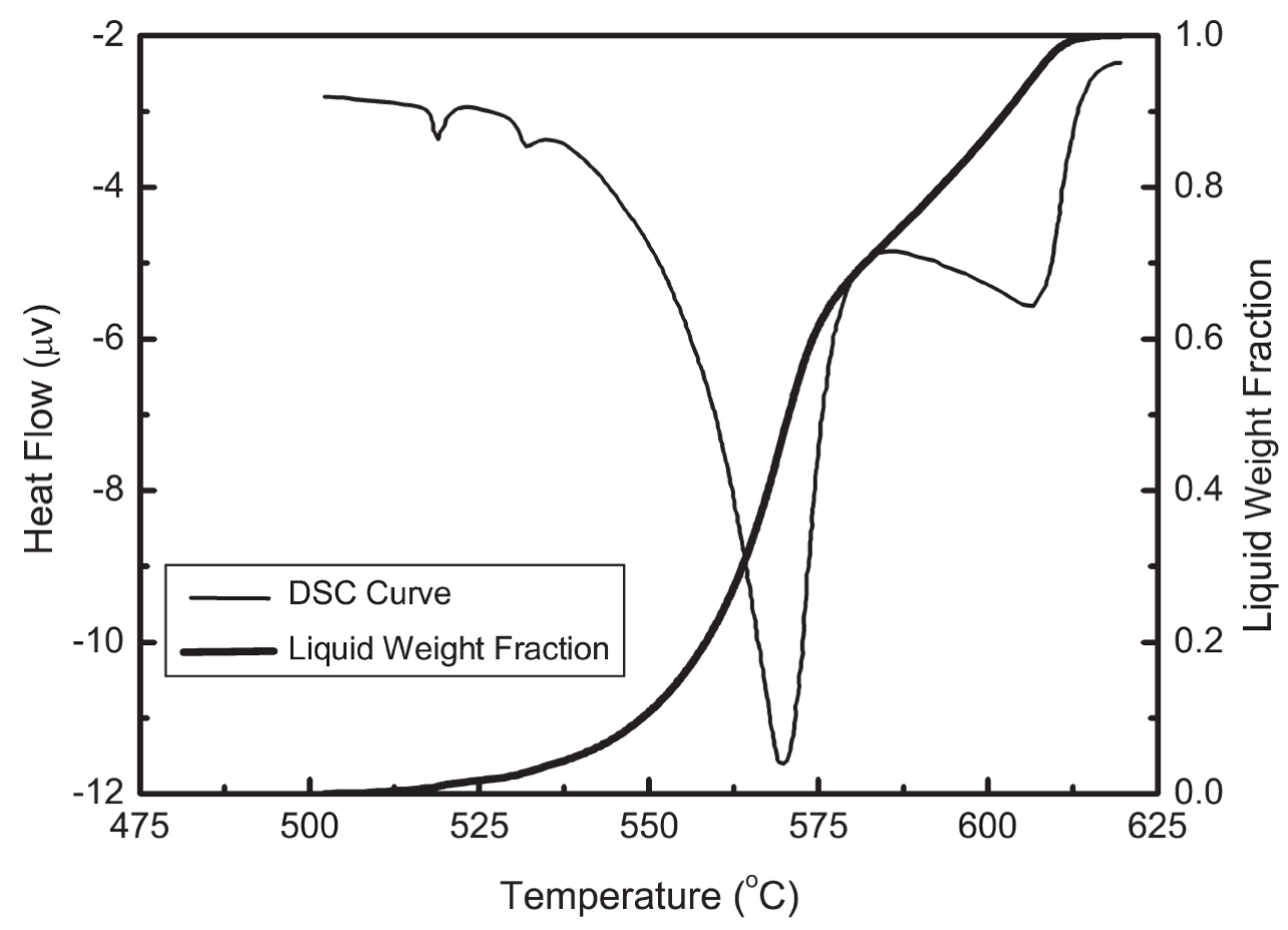

Fig. 1. DSC and liquid weight fraction versus temperature curves for A319 alloy.

solidus and liquidus temperatures of the $\mathrm{A} 319$ alloys are $507^{\circ} \mathrm{C}$ and $\sim 611^{\circ} \mathrm{C}$, respectively. It is clear from DSC curve shown in Fig. 1 that, there are two main peaks in the curve. These peaks represent the phase transformation processes taking place during heating of the alloy. The first peak represents the process of melting of the eutectic phase. This process starts at about $540^{\circ} \mathrm{C}$ and finishes at $580^{\circ} \mathrm{C}$. The second peak represents the melting process of the alpha ( $\left.\alpha-\mathrm{Al}\right)$ phase. This process starts after the complete melting of the eutectic phase and finishes at about $611^{\circ} \mathrm{C}$.

About $1.5 \mathrm{~kg}$ of the A319 alloy was melted in a graphite crucible in a resistance furnace at $680{ }^{\circ} \mathrm{C}$. The molten metal was then allowed to cool down to the pouring temperature of $600{ }^{\circ} \mathrm{C}, 620{ }^{\circ} \mathrm{C}$ and $640{ }^{\circ} \mathrm{C}$. The melt was then continuously poured on a plate of $100 \mathrm{~mm}$ wide and collected into a steel mould. The steel mould had a diameter of $50 \mathrm{~mm}$ and height of $160 \mathrm{~mm}$ with a draft angle of $2^{\circ}$ for easy removal of the solidified ingot. The plate is made from mild steel and coated with a thin layer of hard Chromium to prevent adhesion between the molten metal and the plate. The cooling plate was fixed at 60 - with respect to the horizontal plane and was cooled with water circulation underneath. The cooling slope apparatus used in this study is shown in Fig. 2. Pouring was carried out with and without water cooling circulation. 


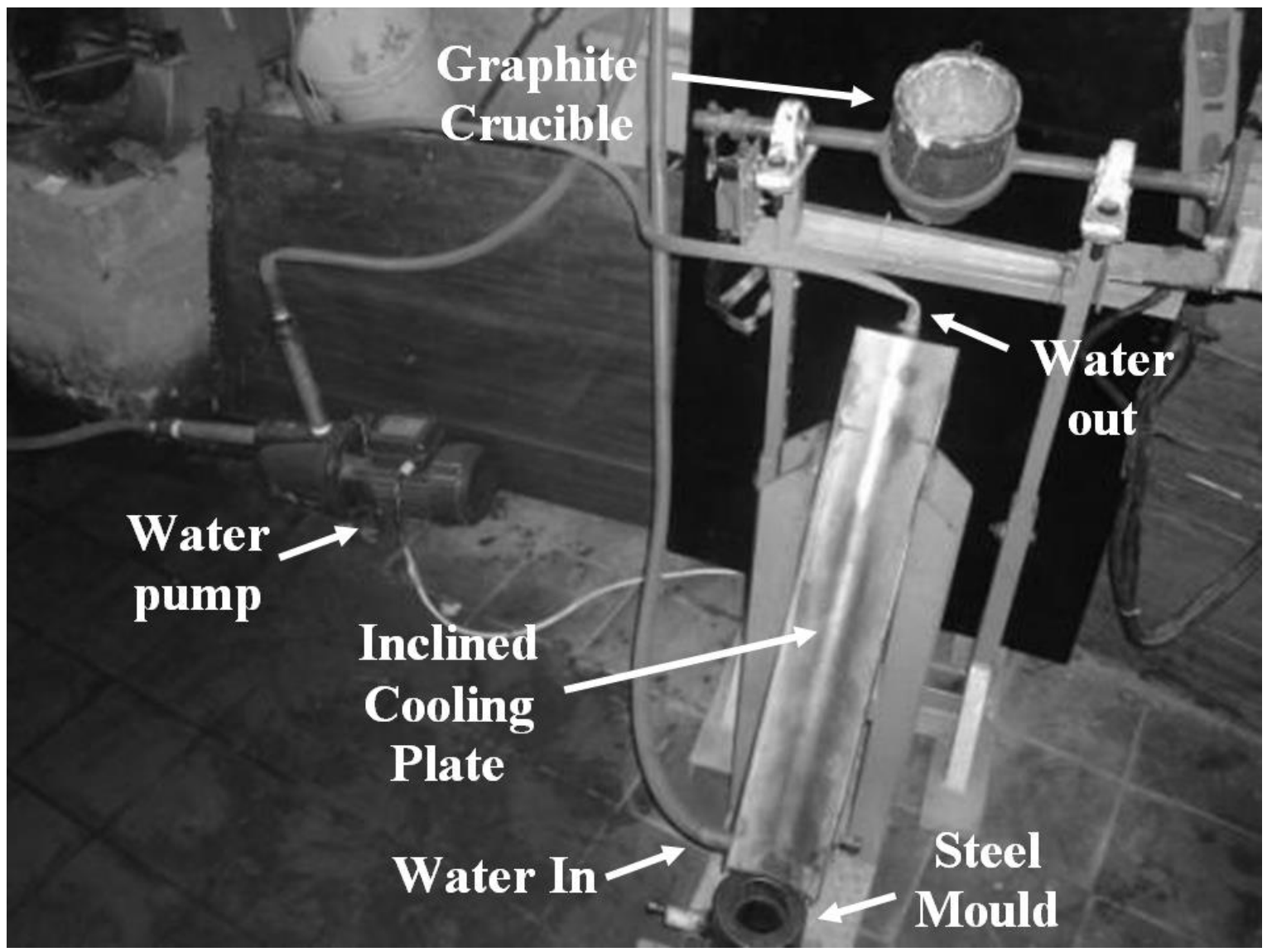

Fig. 2. Cooling slope casting apparatus used in the present work.

The flow length of the molten metal over the plate was also fixed at $500 \mathrm{~mm}$. The water cooling circulation system consists of a water tank, a water pump and a thermometer which was located in the water tank. The water was pumped from the bottom to the top of the plate with a flow rate of $20 \mathrm{lit} / \mathrm{min}$ and a temperature of about $20{ }^{\circ} \mathrm{C}$.

Figure 3 shows a photograph of a sample ingot produced from the CS casting process. The upper part of the ingot with $35 \mathrm{~mm}$ height that contains the shrinkage cavity was removed from the ingot. The remained part of the ingot was cut longitudinally into two parts and prepared for macrostructual examinations. Transverse metallographic samples were cut from the top and bottom of the remained ingots and then ground, and polished for microstructural examinations (see Fig. 3). Macroetching was carried out using a chemical solution consists of $250 \mathrm{ml}$ $\mathrm{H}_{2} \mathrm{O}, 15 \mathrm{ml} \mathrm{HNO}_{3}, 15 \mathrm{ml} \mathrm{HF}$ and $45 \mathrm{ml} \mathrm{HCl}$ for $10-15$ seconds at ambient temperature. Microetching was carried out using a chemical solution consists of 0.5 $\mathrm{ml} \mathrm{HF} 40 \%+100 \mathrm{ml} \mathrm{H}_{2} \mathrm{O}$ for 5-60 s at an ambient temperature.

The bulk porosity of the ingots produced from the CS casting were measured using water displacement technique (Archimedes principle). Analysis on the size and shape factor (SF) of the primary a-Al grains were carried out using image-analyzing techniques. The average size of $\alpha-A l$ grains were measured by the linear intercept 


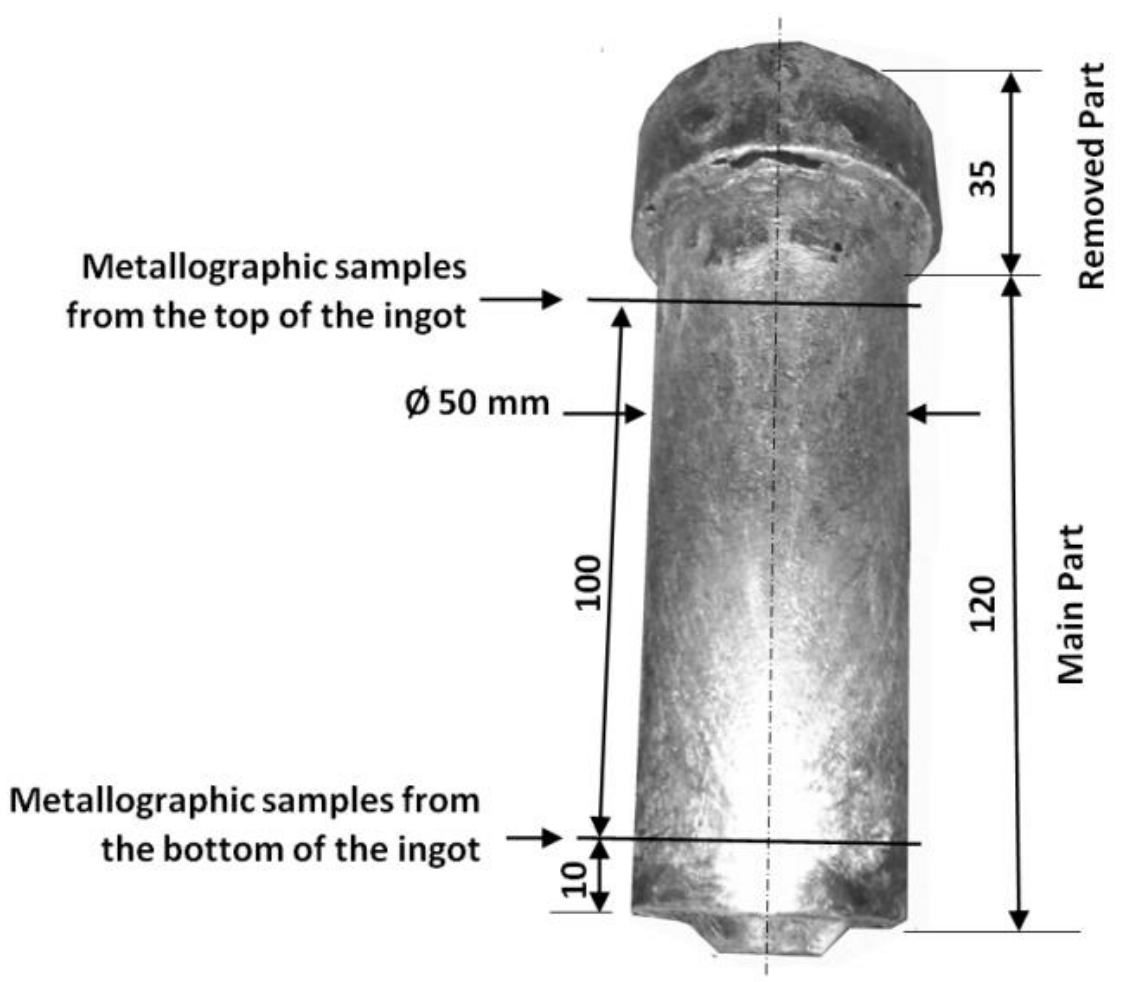

\section{Dimensions in $\mathrm{mm}$}

Fig. 3. A photograph of the produced ingot showing its main dimensions and the position of metallographic samples.

method according to the ASTM-E112-96 [19]. The shape factor was determined from the following equation:

$$
\mathrm{SF}=\mathrm{P}^{2} / 4 \pi \mathrm{A}
$$

where $P$ is the perimeter and $A$ is the area of $\alpha$-Al grain. For a perfect circle, the shape factor would be one. Figure 4 shows the change of microstructure in terms of shape factor [11].

The microhardness of the samples was measured using Vickers's microhardness tester. The microhardness profiles along the longitudinal as well as the radial sections of the ingot were measured using a load of $500 \mathrm{~g}$ for 15 seconds.

\begin{tabular}{|c|c|}
\hline Shape Factor (SF) & Typical Particle Shape \\
\hline $\mathrm{F} \geq 1$ & \\
\hline $\mathrm{F} \geq 3 \geq \mathrm{F} \geq 2$ &
\end{tabular}

Fig. 4. The change of microstructure in terms of shape factor. 


\section{RESULTS AND DISCUSSION}

\section{The Porosity of CS Ingots}

Figure 5 shows a typical macrograph of the longitudinal cross-section of the ingots produced using CS casting at different pouring temperatures and with and without water cooling. It is seen that large pores are observed at the upper part of the CS cast ingot. Such large pores were only observed for CS cast ingots poured at $600{ }^{\circ} \mathrm{C}$ (i.e. the lowest pouring temperature). However, the size and quantity of the pores were reduced by using the water cooling (compare between Figure $5 \mathrm{a}$ and $5 \mathrm{~b}$ ). Ingots poured at higher pouring temperatures than $600^{\circ} \mathrm{C}$ (i.e. $620{ }^{\circ} \mathrm{C}$ and $640{ }^{\circ} \mathrm{C}$ ) did not show any large pores all over the ingot.

Figure 6 shows the variation of the bulk porosity of the CS cast ingots with the pouring temperatures. It has been found that the bulk porosity of the CS cast ingots varies between $3.13 \mathrm{vol} . \%$ and $3.75 \mathrm{vol} .-\%$. At pouring temperatures of 600 and 620 ${ }^{\circ} \mathrm{C}$, the ingots poured with water-cooling exhibited slightly lower porosity content than those poured without water-cooling. For example, at constant pouring temperature of $600{ }^{\circ} \mathrm{C}$, the CS cast ingots produced with and without water-cooling showed bulk porosity of 3.54 vol.- $\%$ and 3.75 vol.-\%, respectively. However, at the highest pouring temperature (i.e. $640{ }^{\circ} \mathrm{C}$ ), the bulk porosity contents of CS cast ingots produced with and without water cooling were practically the same as shown in Fig. 6 . It has been found also that increasing the pouring temperature slightly reduces the bulk porosity of the CS cast ingots. For example, increasing the pouring temperature from $600{ }^{\circ} \mathrm{C}$ to $640^{\circ} \mathrm{C}$ reduced the bulk porosity of the CS cast ingots from 3.75 vol.$\%$ to 3.13 vol.- $\%$ for the ingots poured without water-cooling.

\section{The Microstructure of CS Cast Ingots}

The microstructure of the conventionally cast A319 ingot is shown in Fig. 7. The figure shows that the microstructure contains coarse dendrites of primary $\alpha-\mathrm{Al}$ phase. It has been found that the dendrites of $\alpha$-Al phase have size more than 350 $\mu \mathrm{m}$ while the average secondary dendrite arm spacing (SDAS) of $\alpha$-Al phase in the conventionally as-cast sample was $\sim 18 \mu \mathrm{m}$. Figures 8 and 9 shows typical microstructures of the CS cast ingots produced using several processing conditions of pouring temperatures and water cooling. The microstructure of the CS ingot is significantly different from the conventionally cast A319 ingot shown in Fig. 7 . The CS cast ingots showed non-dendritic microstructure of the primary $\alpha$-Al phase. The differences between the two microstructures shown in Figs. 8 and 9 are illustrated in Fig. 10 in terms of variation in shape factor where larger shape factors indicate coarser grains.

Figure 10 shows the variation of the shape factor (SF) of primary $\alpha$-Al grains with the position at the transverse section of the ingots. It can be seen that the primary $\alpha-\mathrm{Al}$ grains have generally higher shape factor near the edge of ingot than the middle and center. For example, ingots poured at $600{ }^{\circ} \mathrm{C}$ without water-cooling, the $\alpha$-Al grains showed shape factors of 1.75 and 2.21 at the center and radius positions of the ingots, respectively. This observation was noticed for ingots poured with and without water-cooling. The water-cooled CS cast ingots exhibited lower shape factor when compared with those casted without water-cooling. For example, at $620^{\circ} \mathrm{C}$, ingots 


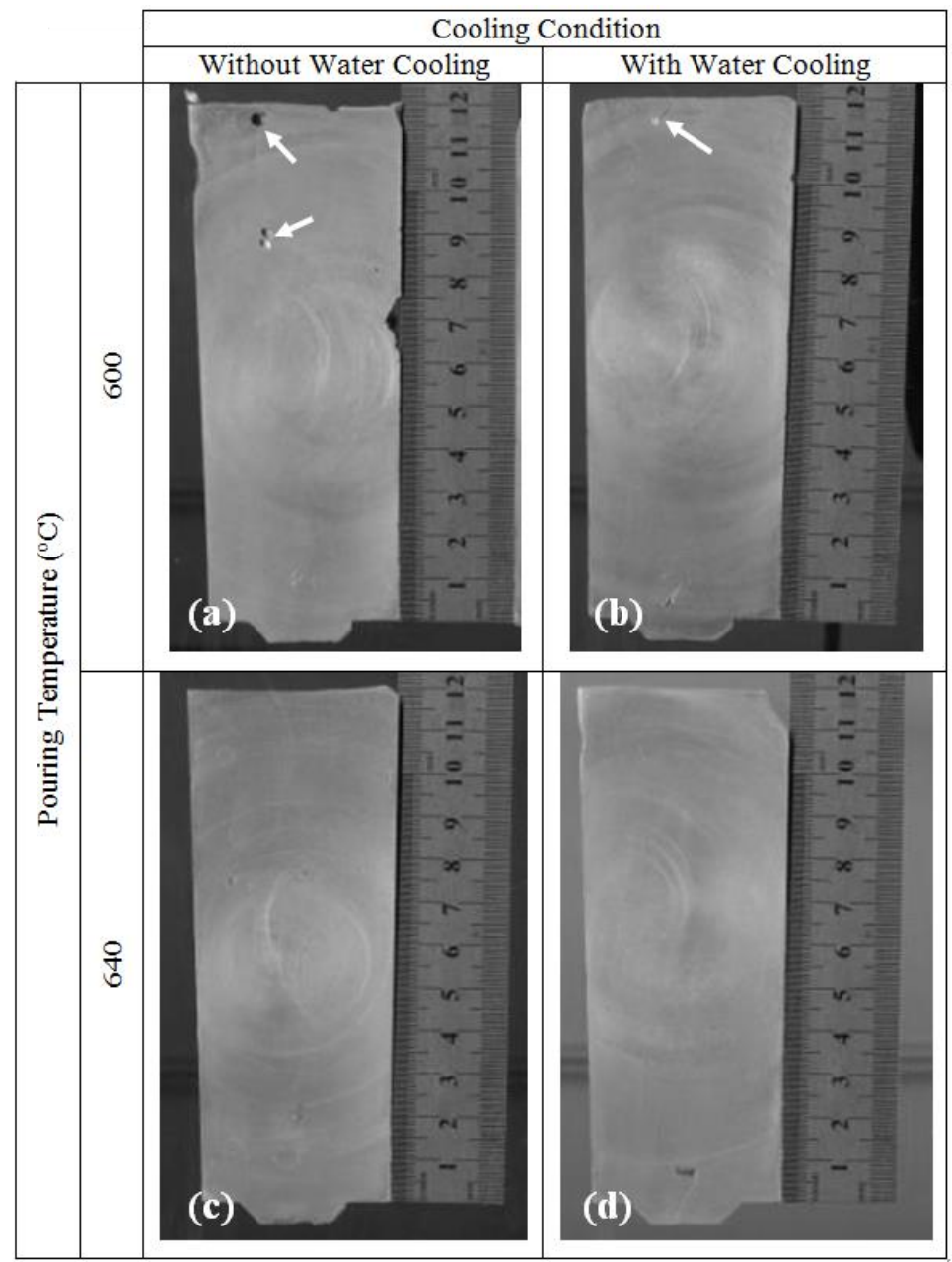

Fig. 5. Typical macrograph of the longitudinal cross-section of ingots produced using CS casting with and without water-cooling and different pouring temperatures.

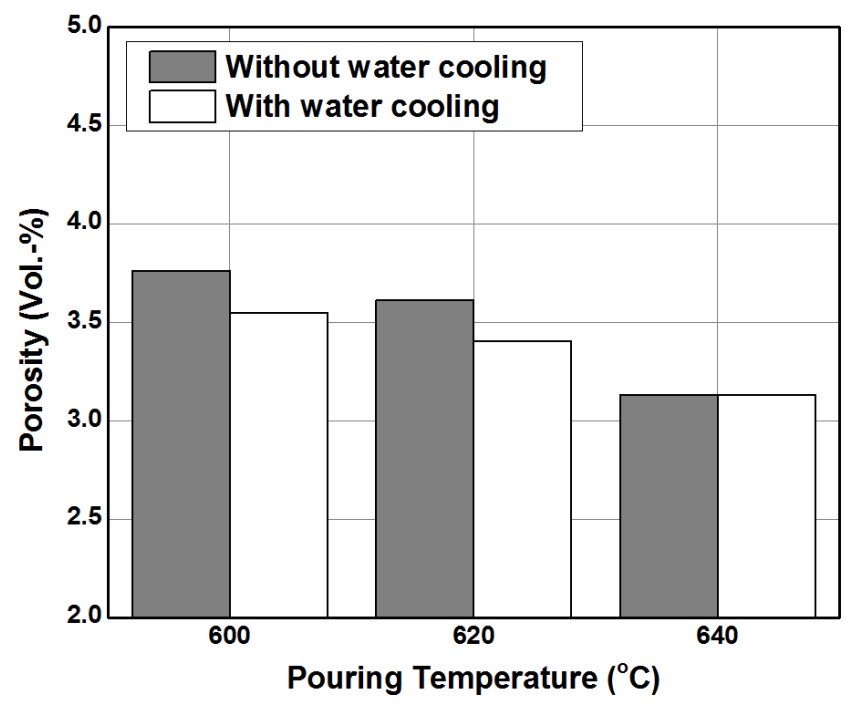

Fig. 6. Variation of the bulk porosity of the CS cast ingots with the pouring temperatures. 


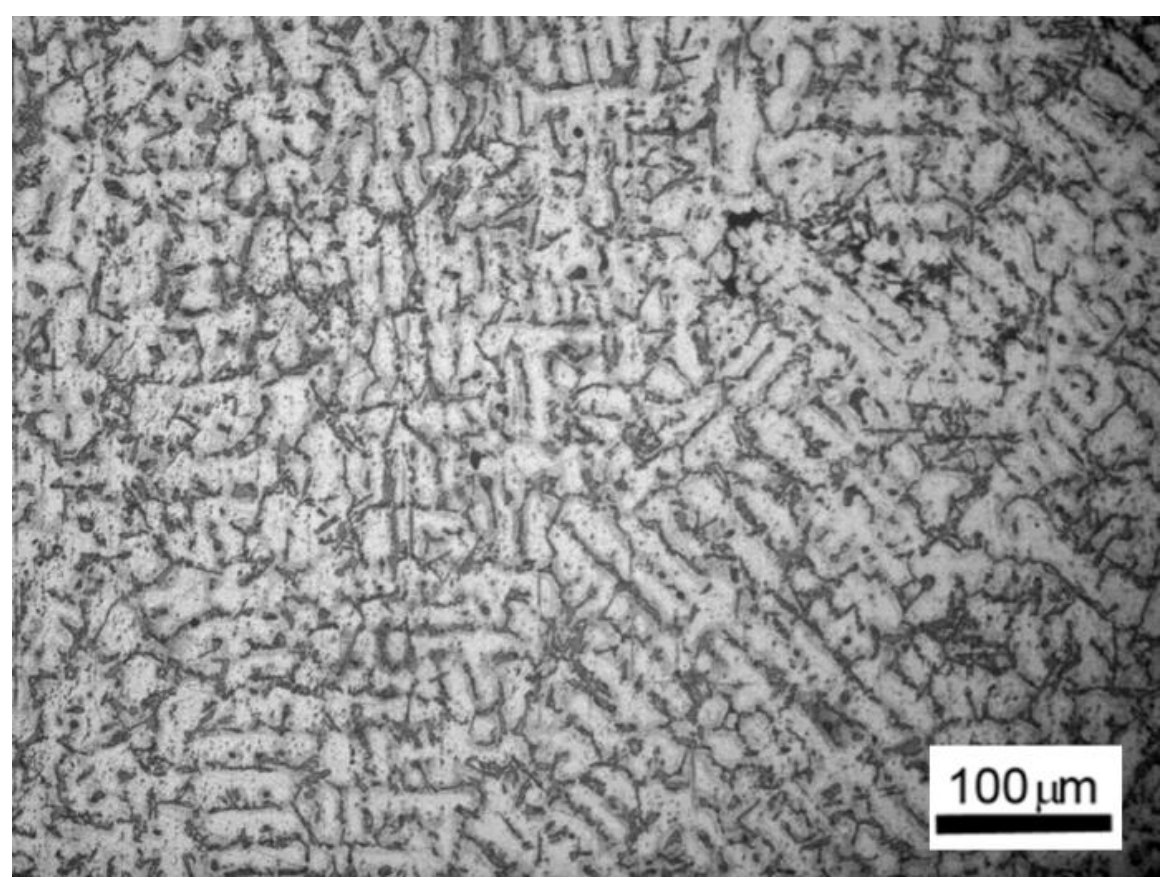

Fig. 7. Microstructures of the conventionally cast A319 Al-Si alloy.

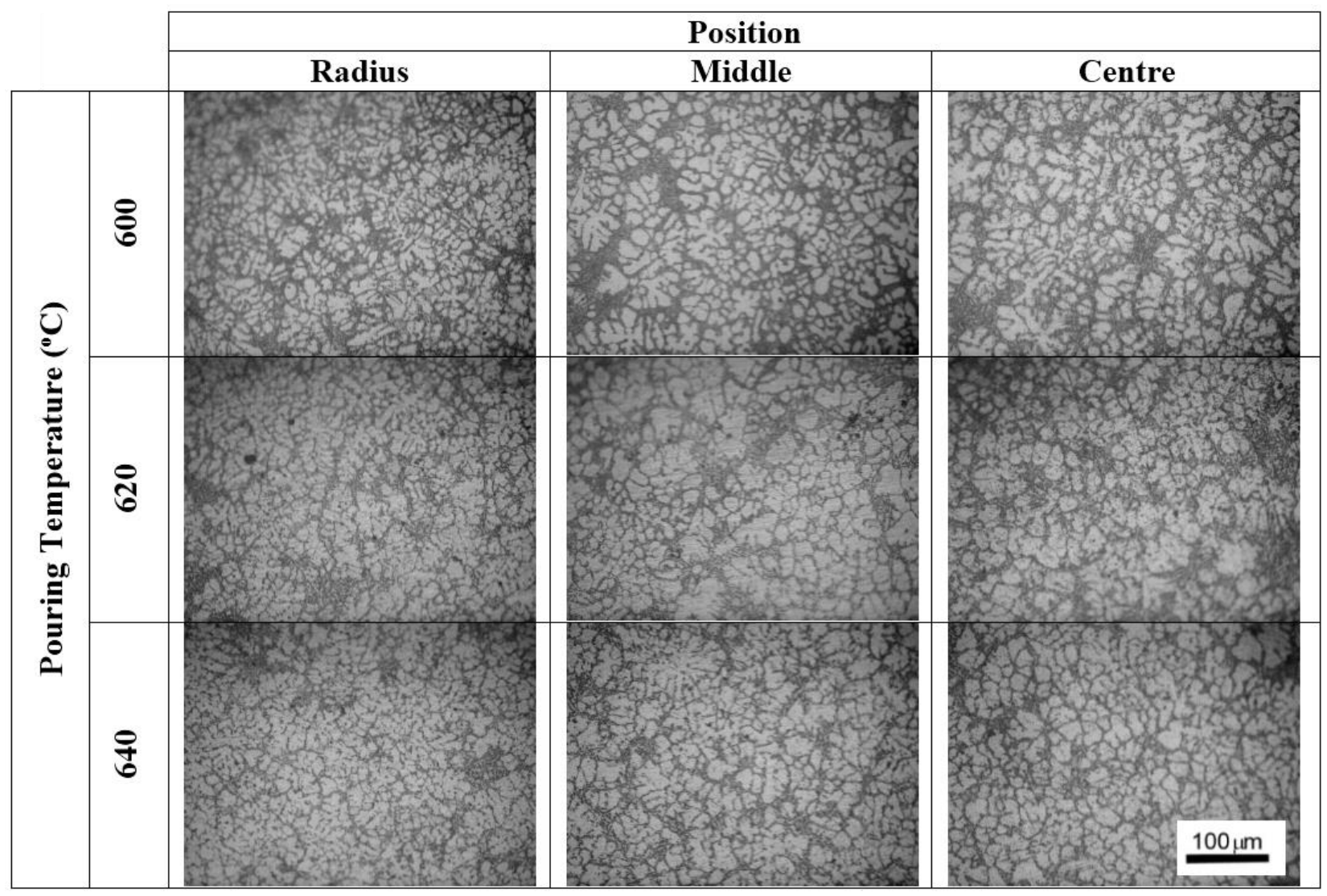

Fig. 8. Microstructures of CS cast ingot without water-cooling. 


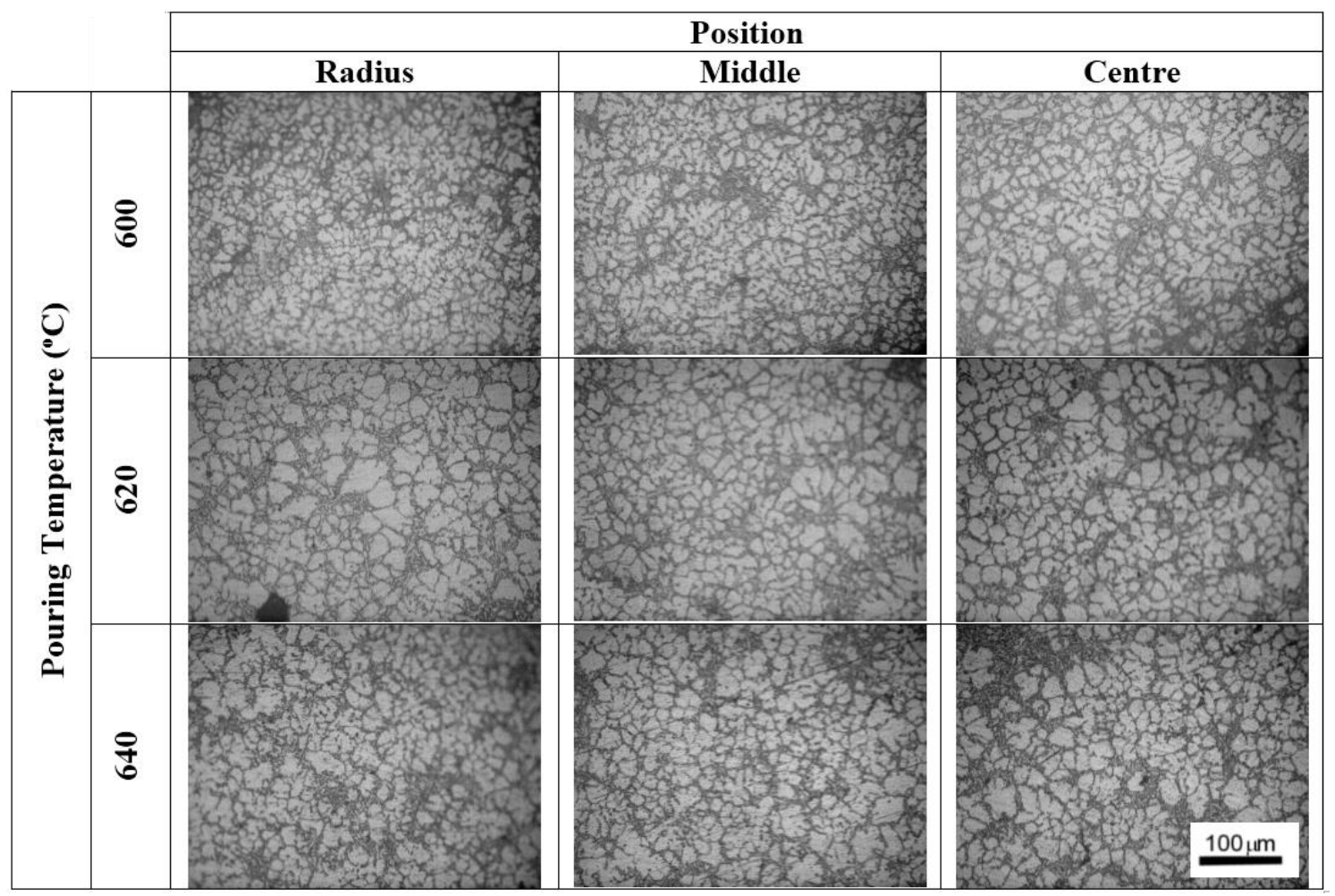

Fig. 9. Microstructures of CS cast ingot with water-cooling.

poured with- and without water-cooling exhibited shape factors of 1.66 and 1.85 , respectively, at the center of the ingots. The results showed also that increasing the pouring temperature increasing the shape factor of the $\alpha$-Al grains. This observation was noticed for both conditions of cooling (i.e. with and without water-cooling). For example, the center of CS cast ingots poured with water-cooling exhibited shape factors of $1.47,1.663$ and 1.81 at $600{ }^{\circ} \mathrm{C}, 620^{\circ} \mathrm{C}$ and $640^{\circ} \mathrm{C}$, respectively.

Figure 11 shows the effect of pouring temperature on the size of primary $\alpha$-Al grains. The results revealed that the primary $\alpha-A l$ grains lower average grain size near the edge of ingot than the middle and center. Such observation was noticed for CS cast ingots poured with and without water-cooling. For example, ingots poured at $600{ }^{\circ} \mathrm{C}$ without water-cooling, the $\alpha$-Al grains showed average size of 33,28 and $22 \mu \mathrm{m}$ at the center, middle and radius positions of the ingots, respectively. The CS cast ingots poured with water-cooling exhibited slightly lower average grain size of the primary $\alpha$-Al grains than those poured without water-cooling. For example, ingots poured at $620{ }^{\circ} \mathrm{C}$ with and without water-cooling exhibited average size of $\alpha-\mathrm{Al}$ grains of 37 and $35 \mu \mathrm{m}$ at the central position of the ingots, respectively. It is clear from Fig. 11 that increasing the pouring temperature increases the average size of the primary $\alpha-A$ I grains. For example, the center of CS cast ingots poured with watercooling exhibited average size of the primary $\alpha-A$ l grains of $30,35.3$ and $37.4 \mu$ mat $600{ }^{\circ} \mathrm{C}, 620^{\circ} \mathrm{C}$ and $640^{\circ} \mathrm{C}$, respectively. 

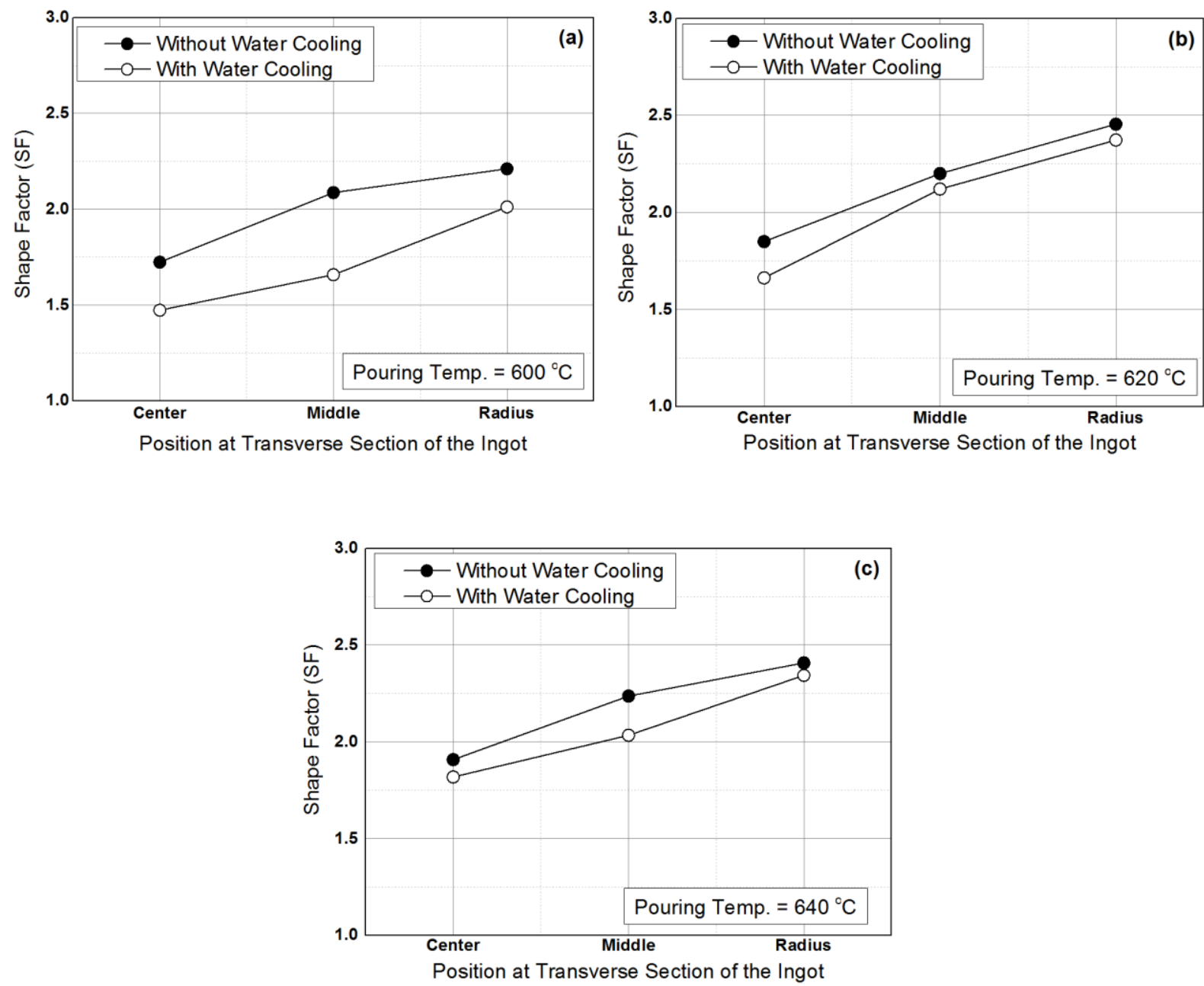

Fig. 10. Variation of the shape factor of primary $\alpha-A l$ grains with the position at the transverse section of the ingots.
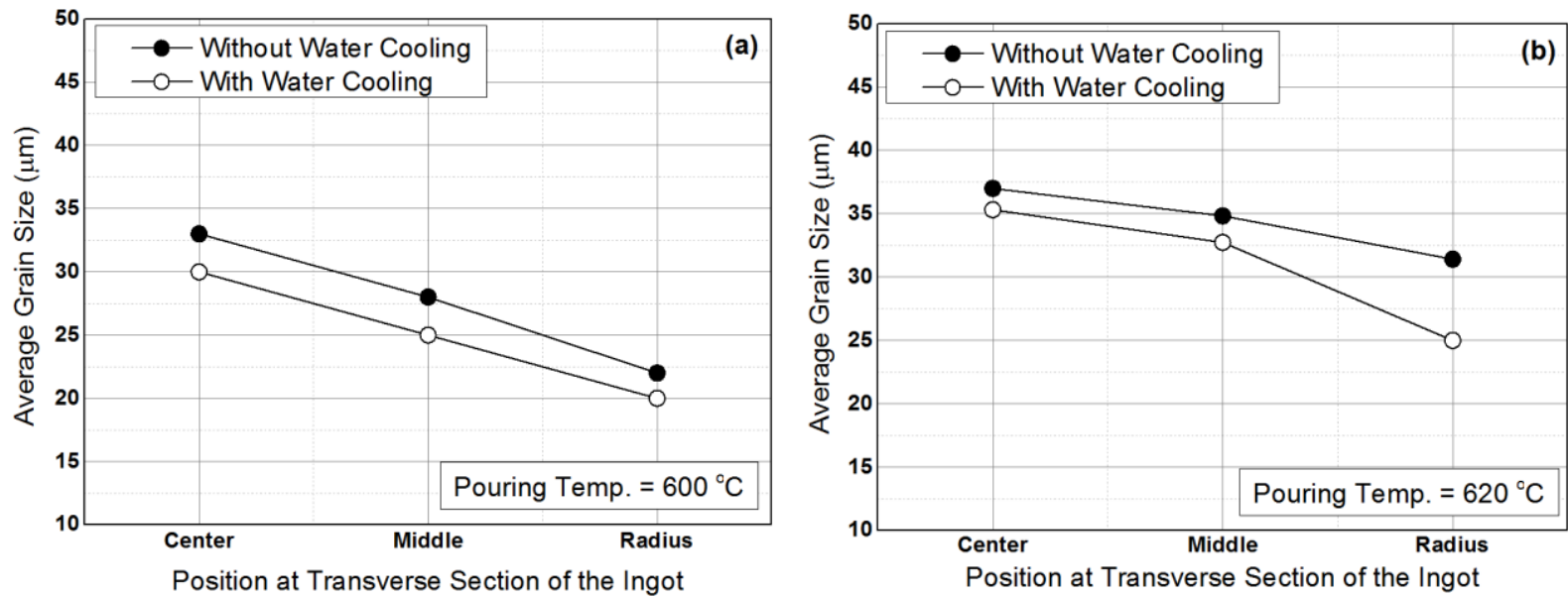


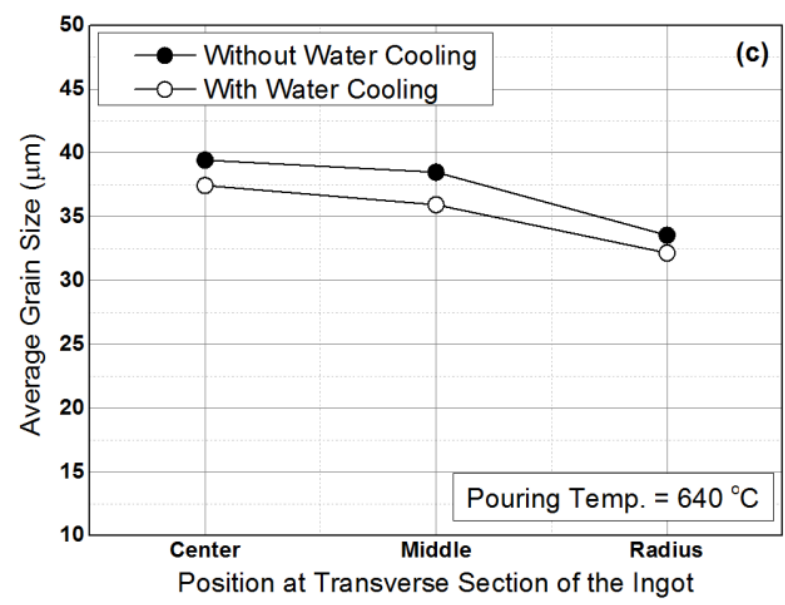

Fig. 11. Variation of the grain size of primary $\alpha$-Al grains with the position at the transverse section of the ingots.

In the present investigation, the introduction of water-cooling reduced the size of the primary a-Al grains of the CS cast ingots. It is believed that the introduction of watercooling has caused the molten metal to cool faster while flowing down the cooling slope. In solidification process, the nucleation and spherodisation can be influenced by cooling rate [11]. Increasing the cooling rate can promote the nucleation rate. The change of the nucleation rate influences the grain size and the shape factor of the primary $\alpha-A l$ grains. In the case of pouring without water-cooling, the number of crystals nucleated and detached from the surface of the cooling plate was insufficient to produce fine and spheroidal primary crystals. The introduction to water-cooling leads to higher fractional solidification on the cooling plate and increase the rate of nucleation and detachment of the $\alpha$-Al crystals resulted in finer and non-dendritic primary $\alpha$-Al grains. High pouring temperature leads to decreased nucleation and tendency to remelting of the primary crystals, and undesired grain growth. Low pouring temperature causes rapid solidification of the melt on the slope promoting dendritic solidification.

\section{The Hardness of CS Cast Ingots}

Figure 12 shows the results of the hardness measurements along the longitudinal section of the CS cast ingots. All the CS cast ingots exhibited scatter hardness values along the longitudinal section. The CS cast ingots poured with water-cooling exhibited higher hardness than those poured without water-cooling. It has been found also that increasing the pouring temperature increases the average hardness of the CS cast ingots. For example, the water-cooled CS cast ingots poured at 600, 620 and $640{ }^{\circ} \mathrm{C}$ exhibited average hardness of about 43, 50 and $55 \mathrm{VHN}$, respectively. The increase of the hardness of water-cooled CS cast ingots may attribute to the smaller grain size exhibited by such ingots in comparison with the CS cast ingots without water-cooling. The relationship between the hardness $\left(H_{v}\right)$ in the stirred zone and the grain size (d) can be explained using the Hall-Petch equation [20].

$$
\mathrm{H}_{\mathrm{v}}=\mathrm{H}_{\mathrm{O}}+\mathrm{k}_{\mathrm{H}} \mathrm{d}^{-1 / 2}
$$


where $\mathrm{H}_{\mathrm{o}}$ and $\mathrm{k}_{\mathrm{H}}$ are appropriate constants. It is clear from equation (2) that $\mathrm{H}_{\mathrm{v}}$ is proportional to $\mathrm{d}^{-1 / 2}$. Accordingly, the finer the grain size is, the higher the hardness value is. The increase of the hardness due to water-cooling of CS cast ingots was reported by Budiman et al. [11]. They showed that the addition of water-cooling has resulted with an increase in average microhardness of CS cast A359 ingots from 74 to $82 \mathrm{VHN}$.
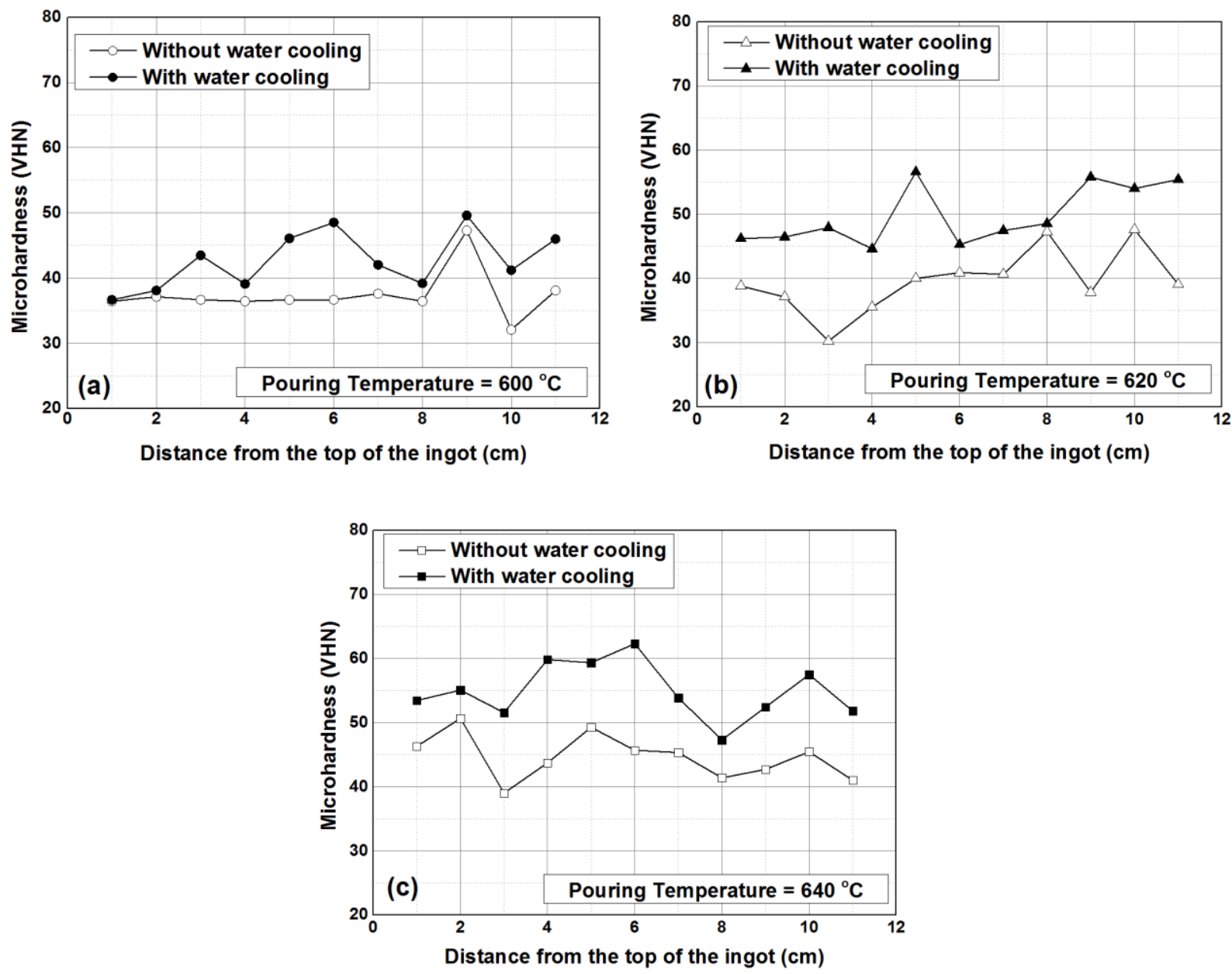

Fig. 12. Variation of the hardness along the longitudinal section of the CS cast ingots.

\section{CONCLUSIONS}

Based on the results presented, the following conclusions can be drawn:

1. Cooling slope (CS) cast ingots poured with water-cooling exhibited slightly lower bulk porosity than those poured without water-cooling. Increasing the pouring temperature slightly reduces the bulk porosity of the CS cast ingots.

2. The water-cooled CS cast ingots exhibited lower shape factor when compared with those cast without water-cooling. Increasing the pouring temperature increases the shape factor of the $\alpha$-Al grains.

3. The CS cast ingots poured with water-cooling exhibited slightly lower average grain size of the primary $\alpha-A l$ grains than those poured without water-cooling. 
Increasing the pouring temperature increases the average size of the primary $\alpha$ Al grains.

4. The CS cast ingots poured with water-cooling exhibited higher hardness than those poured without water-cooling. Increasing the pouring temperature increases the average hardness of the CS cast ingots.

\section{ACKNOWLEDGMENTS}

The authors are thankful to Benha University - Shoubra Faculty of Engineering for providing financial support and facilities for carrying out this work.

\section{REFERENCES}

[1] FarshidTaghavi, Ali Ghassemi, "Study on the effects of the length and angle of inclined plate on the thixotropic microstructure of A356 aluminum alloy", Technical Report, Materials and Design, 30, 2009, pp. 1762-1767.

[2] C.G. Kang, P.K.Seo, M.D. Lim,"Rheo and thixo die casting for automobile suspension parts", In: Proceedings of the $8^{\text {th }}$ international conference onsemisolid processing of alloys and composites, Cyprus, 2004.

[3] T. Haga, R. Nakamura, R. Tago, H. Watari, "Effects of casting factors of cooling slope onsemisolid condition", Trans. Nonferrous Met. Soc. China, 20, 2010, pp. s968-s972.

[4] P. Kapranos, D.H. Kirkwood, H.V. Atkinson, J.T. Rheinlander, J.J. Bentzen, P.T. Toft, C.P. Debel, G. Laslaz, L. Maenner, S. Blais, J.M. Rodriguez-lbabe, L. Lasa,P. Giordano, G. Chiarmetta, A. Giese, " Thixoforming of an automotive part in A390 hypereutectic Al-Si alloy", Journal of Materials Processing Technology, 135, 2003, pp. 271-277.

[5] M. Paes, E.J. Zoqui, "Semi-solid behavior of new Al-Si-Mg alloys for thixoforming", Materials Science and Engineering A, 406, 2005, pp. 63-73.

[6] E. de Freitas, M. Ferrante, V.F. da Silva, W. Bose Filho, D. Spinelli, "Thixoextrusion of an A356 alloy: microstructural studies and high temperature fatigue behaviour", Journal of Materials Processing Technology, 155-156, 2004, pp. 1629-1633.

[7] P. Kapranos, P.J. Ward, H.V. Atkinson, D.H. Kirkwood, "Near net shaping by semi-solid metal processing", Materials and Design, 21, 2000, pp. 387-394.

[8] Y. Birol,"A357 thixoforming feedstock produced by cooling slopecasting", J. Mater. Processing Technol.,186, 2007, pp. 94-101.

[9] E.C. Legoretta, H.V. Atkinson, H. Jones, "Cooling slope casting to obtain thixotropic feedstock II: observations with A356 alloy", Journalof Materials Science, 43 (16), 2008, pp. 5456-5469.

[10] F. Taghavi, H. Saghafian, Y.H.K. Kharrazi, "Study on the ability of mechanical vibration for the production of thixotropic microstructure in A356 aluminium alloy", Materials and Design, 30(1), 2009, pp. 115-121.

[11] H. Budiman, M.Z. Omar, A. Jalar, A.G. Jaharah, " Effect of Water Cooling on the Production of Al-Si Thixotropic Feedstock by Cooling Slope Casting", European Journal of Scientific Research, 32 (2), 2009, pp.158-166.

[12] YucelBirol, "Cooling slope casting and thixoforming ofhypereutectic A390 alloy", journal of materials processing technology, 207, 2008, pp. 200-203. 
[13] E. Cerri, E. Evangelista, S. Spigarelli, P. Cavaliere, F. DeRiccardis, " Effects of thermal treatments on microstructure and mechanical properties in a thixocast 319 aluminum alloy", Materials Science and Engineering A, 284, 2000, pp. 254-260.

[14] M. S. Salleh, M. Z. Omar, J. Syarif, M. N. Mohammed, "Review Article: An Overview of Semisolid Processing of Aluminium Alloys", ISRN Materials Science, 2013, Article ID 679820, pp. 1-9.

[15] H. V. Atkinson, "Alloys for semi-solid processing", Solid State Rhenomena, 192193, 2012, pp. 16-27.

[16] M.S. Salleh, M.Z. Omar, J. Syarif, M.N. Mohammed, "Thermodynamic Modeling on the Mutual Effect of Copper, Manganese and Iron Addition in Al-Si-Cu For Semisolid Processing", Journal of Asian Scientific Research, 2(11), 2012, pp. 614-619.

[17] F.C. Robles Hernandez, J.H. Sokolowski, "Effects and on-line prediction of electromagnetic stirring on microstructurerefinement of the $319 \mathrm{Al}-\mathrm{Si}$ hypoeutectic alloy", Journal of Alloys and Compounds, 480, 2009, pp. 416-421.

[18] P. Cavaliere, E. Cerri, P. Leo, "Effect of heat treatments on mechanical properties and damageevolution of thixoformedaluminium alloys", Materials Characterization, 55, 2005, pp 35- 42.

[19] ASTM Standard, E112-96, "Standard Test Methods for Determining Average Grain Size", 2004.

[20] A. S. Taha, F. H. Hammad, "Application of the Hall-Petch Relation to Microhardness Measurements on Al, Cu, Al-MD 105, and Al-Cu Alloys", physica status solidi (a), 119(2), 1990, pp. 455-462. 